\title{
Moisture-dependent orthotropic tension-compression asymmetry of wood
}

\section{Journal Article}

\section{Author(s):}

Ozyhar, Tomasz; Hering, Stefan; Niemz, Peter

Publication date:

2013-05

Permanent link:

https://doi.org/10.3929/ethz-b-000059139

Rights / license:

In Copyright - Non-Commercial Use Permitted

Originally published in:

Holzforschung 67(4), https://doi.org/10.1515/hf-2012-0089 
Tomasz Ozyhar*, Stefan Hering and Peter Niemz

\section{Moisture-dependent orthotropic tension- compression asymmetry of wood}

\begin{abstract}
The influence of moisture content (MC) on the tension-compression (Te-Co) asymmetry of beech wood has been examined. The elastic and strength parameters, including Te and Co Young's moduli, Poisson's ratios, and ultimate and yield stress values, were determined and compared in terms of different MCs for all orthotropic directions. The results reveal a distinctive Te-Co strength asymmetry with a moisture dependency that is visualized clearly by the Te to Co yield stress ratio. The Te-Co asymmetry is further shown by the inequality of the elastic properties, known as the "bimodular behavior". The latter is proven for the Young's moduli values in the radial and tangential directions and for individual Poisson's ratios. Although the bimodularity of the Young's moduli is significant at low MC levels, there is no evidence of moisture dependency on the Te-Co asymmetry of the Poisson's ratios.
\end{abstract}

Keywords: bimodular behavior, moisture content, Poisson's ratios, strength, tension-compression asymmetry, Young's moduli

\footnotetext{
*Corresponding author: Tomasz Ozyhar, Institute for Building Materials (Wood Physics), ETH Zurich, 8093 Zurich, Switzerland, Phone: +4144633 9179, Fax: +41 44632 11774,

e-mail: ozyhart@ethz.ch

Stefan Hering: Institute for Building Materials (Computational Physics for Engineering Materials), ETH Zurich, 8093 Zurich, Switzerland

Peter Niemz: Institute for Building Materials (Wood Physics), ETH Zurich, 8093 Zurich, Switzerland
}

\section{Introduction}

The influence of moisture content (MC) on the mechanical properties of wood in general is well known (as reviewed by Gerhards 1982). However, little attention has been paid to the moisture-dependent elasticity, particularly in the radial (R) and tangential (T) directions (McBurney and Drow 1962; Neuhaus 1983; Hering et al. 2012a; Ozyhar et al. 2012a). In some references (e.g. Kretschmann and Green 1996), the influence of the anatomical direction on the elastic properties was not considered (no distinction is made between the $\mathrm{R}$ and the T). Further, although the influence of MC on the Young's and shear moduli is known in principle (Gerhards 1982; Bodig and Jayne 1993; Niemz 1993), the moisture dependency of the Poisson's ratios remains unclear. The results of the few works investigating the influence of MC on the Poisson's ratios for wood (McBurney and Drow 1962; Hering et al. 2012a) are partially inconsistent and therefore do not explain the moisture dependency of the Poisson's ratios.

It is frequently assumed that the elastic properties for wood in tension ( $\mathrm{Te}$ ) and compression (Co) are equal (Kollmann and Cote 1984; Niemz 1993), but some considerable presumptions exist, suggesting that this might not be the case. Conners and Medvecz (1992) found a Te-Co asymmetry for the longitudinal (L) Young's moduli of yellow poplar, which was dependent on MC. However, there are no corresponding studies that consider the influence of MC on the Te-Co inequality of the Young's moduli in the $\mathrm{R}$ and $\mathrm{T}$ directions. The same is true for the Poisson's ratios.

Unlike the elastic behavior, the strength asymmetry of wood is better known (Kollmann and Cote 1984; Bodig and Jayne 1993; Ross 2010), that is, wood exhibits higher strength in Te than in Co. However, studies focusing on the moisture dependency of this relationship are widely missing. Interestingly, the influence of MC on the strength properties of wood was recognized early (Tiemann 1906), but a complete data set covering the strength values in Te and $\mathrm{Co}$ as a function of MC in all anatomical directions is not available. Yet, especially in the $\mathrm{R}$ and $\mathrm{T}$ directions, where wood strength is of great importance with regard to the load capacity and failure prediction of wooden structures, the knowledge about the moisture-dependent behavior in these directions is limited to a few references (Kollmann 1956; Goulet 1960; Kufner 1978; Hering et al. 2012b; Ozyhar et al. 2012b).

The present study investigates the influence of MC on the Te and Co mechanical behavior of beech wood. Young's moduli, Poisson's ratios, and ultimate and yield stress values, determined in Te and Co, were investigated as a function of $\mathrm{MC}$ in all anatomical directions (L, R, and T) to characterize the moisture-dependent orthotropic Te-Co relationship of the wood's elastic and strength behavior. 


\section{Materials and methods}

\section{Material and specimen preparation}

The experimental work was performed on European beech wood (Fagus sylvatica L.) grown in Switzerland near Zurich. The average wood density, determined at $20^{\circ} \mathrm{C}$ and $65 \%$ relative humidity (RH), amounted to $669 \pm 21 \mathrm{~kg} \mathrm{~m}^{-3}$. All experiments were carried out with clear wood samples originating from the same wood material.

Three specimen types were prepared for testing (Figure 1a-c): (a) the Te properties in the L direction [according to the DIN 52188 (1979) standard], (b) the Co properties in the L, R, and T directions, and (c) the Te properties in the R and T directions. The "dog-bone"shaped specimen (Figure 1c) is used because its neck-like shape induces failure in the reduced cross-section, which is particularly suitable for testing the Te properties. The cubic specimen (Figure $1 \mathrm{~b}$ ) is well suited for determining the Co properties because it allows the use of an equal specimen for all anatomical directions. Referring to the DIN 52185 (1976) and DIN 52192 (1979) standards, the Co specimen's dimensions tripled the specimen width. The latter was chosen so that the resulting cross-section was similar to that of the Te specimens in the $\mathrm{R}$ and $\mathrm{T}$ directions (Figure $\mathrm{1b}$ and $\mathrm{c}$ ). This guaranteed similar stress distribution in the evaluation area, therefore increasing the comparability of the Te and Co properties in the R and T directions.

Eight groups of moisture conditioned samples were available for testing. The samples in the $\mathrm{R}$ and $\mathrm{T}$ directions were available at eight MC levels; samples in the L direction were due to the time-consuming preparation limited to five MC levels. Specimens were conditioned at various RHs to achieve different wood MCs. As a first step, all specimens were preconditioned at standard climatic conditions $(20 \times C, 65 \% \mathrm{RH})$. After they reached the equilibrium MC (EMC), the specimens' densities were determined by the gravimetric method. Subsequently, all specimens were randomly divided and separated for the specific MC levels, which were achieved in climatic chambers at RHs of $95 \%, 85 \%$, and $65 \%$ and climatic boxes containing different saturated salt solutions at a temperature of $20^{\circ} \mathrm{C}$. The following salt solutions were employed: $\mathrm{LiCl}$ for $12 \% \mathrm{RH}, \mathrm{CH}_{3} \mathrm{CO}_{2} \mathrm{~K}$ for $22 \% \mathrm{RH}$, $\mathrm{CaCl}_{2}$ for $30 \% \mathrm{RH}$, and $\mathrm{NaI}$ for $40 \% \mathrm{RH}$ (RH levels at $20^{\circ} \mathrm{C}$ according to Greenspan 1977). The EMC was reached by exposing the specimen to adsorption (acclimatized at RHs above 65\%) and desorption conditions (acclimatized at RHs below 65\%) for a period of 4-6 weeks. The wood MC $(\omega)$ was determined by the oven-drying method according to the ASTM-D442-92 (2007) standard. The specimen MCs amounted to $\omega=3.3 \%$ for specimens conditioned at $12 \% \mathrm{RH}(\mathrm{LiCl}), \omega=4.7 \%$ at $22 \% \mathrm{RH}\left(\mathrm{CH}_{3} \mathrm{CO}_{2} \mathrm{~K}\right), \omega=5.9 \%$ at $30 \% \mathrm{RH}\left(\mathrm{CaCl}_{2}\right), \omega=6.7 \%$ at $40 \% \mathrm{RH}$ (NaI), $\omega=11.3 \%$ at $65 \% \mathrm{RH}, \omega=14.3 \%$ at $85 \% \mathrm{RH}$, and $\omega=16.3 \%$ at $95 \%$ RH. A separate group of specimens with $\omega \approx 0 \%$ was prepared by oven-drying the specimens at a temperature of $103 \pm 2^{\circ} \mathrm{C}$ (placed in a desiccator before use). To prevent cracking, drying was performed carefully by gradually increasing the temperature.

\section{Experimental procedure}

The experiments consisted of Te and Co tests and were performed under standard climatic conditions immediately after removing the specimen from the climatic box or chamber. The mass of the specimens was recorded twice, that is, directly after removal from the climatic box or chamber and after the test. The increase in MC during the test did not exceed $0.2 \%$; therefore, the MC of the oven-dried specimen is referred to as $\omega \approx 0 \%$. Te and Co displacement-controlled tests were conducted using a Universal Testing Machine (Zwick Z100). A load cell with $100 \mathrm{kN}$ maximum capacity was used for tests performed in the $\mathrm{L}$ direction and a $10 \mathrm{kN}$ load cell was used for tests in

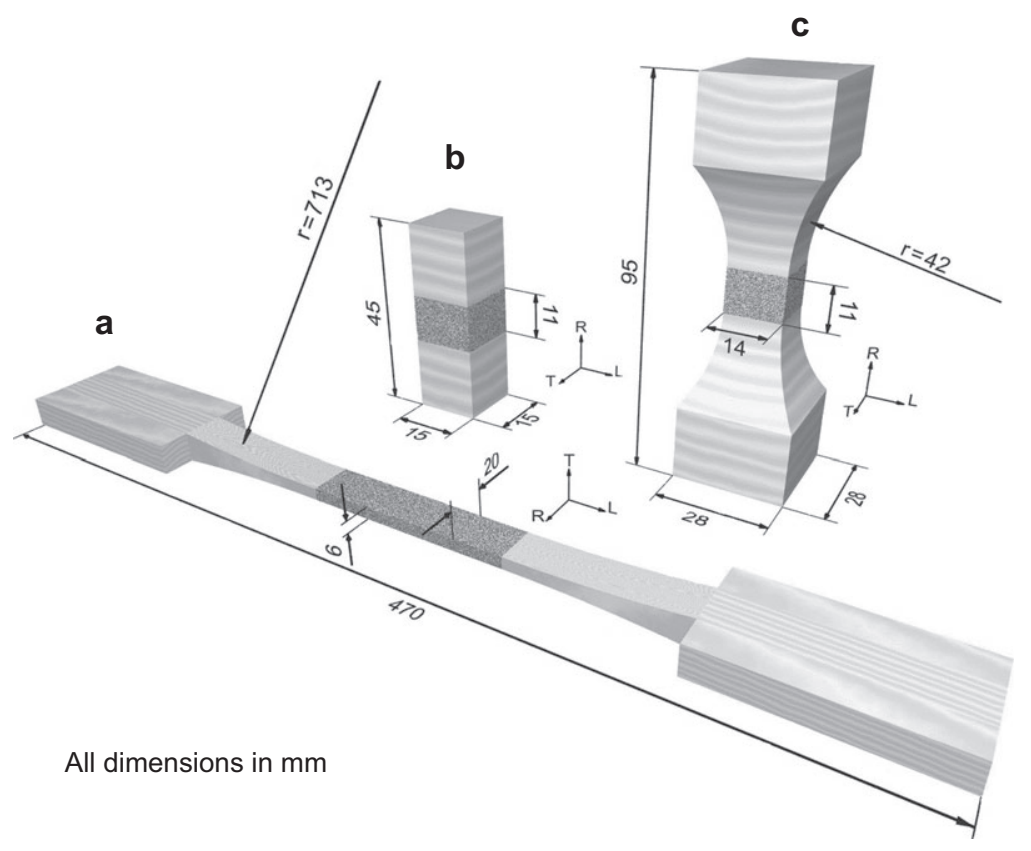

Figure 1 Profile and dimension (all data in $\mathrm{mm}$ ) of specimens with a highly contrasting random dot texture in the cross-section.

(a) Specimen according to the DIN 52188 (1979) standard for Te testing in the L direction. (b) Specimen for the determination of the Co properties in the L, R, and T directions. (c) "Dog-bone"-shaped specimen used to determine the Te properties in the R and T directions. 
the $\mathrm{R}$ and $\mathrm{T}$ directions. A flexible joint was used during Co loading to prevent bending. The specimens were loaded until failure with a constant loading rate so that specimen failure was reached in $90 \pm 30 \mathrm{~s}$, whereby the loading rate was adjusted to the orthotropic direction and the loading direction (Te and Co).

A digital image correlation technique was used to capture the strains during deformation. A high-contrast random dot texture, necessary for the evaluation of the displacements, was sprayed onto the evaluation surface of the specimen (Figure 1). The specimen surface was filmed during the test with a CCD camera. A sequence of images was taken with a frequency of $2 \mathrm{~Hz}$ on the cross-sectional surface area of the specimen. The surface strains were calculated from the displacements that occurred during deformation using the VIC 2D software (Correlated Solution) according to Keunecke et al. (2008).

The Young's moduli $E$ were obtained from the ratio of the stress $\sigma$ to the strain $\varepsilon$ measured in the linear elastic range:

$$
E_{i}=\frac{\Delta \sigma_{i}}{\Delta \varepsilon_{i}}=\frac{\sigma_{i, 2}-\sigma_{i, 1}}{\varepsilon_{i, 2}-\varepsilon_{i, 1}} \quad i \in R, L, T
$$

The specific stress boundaries $\sigma_{i, 1}$ and $\sigma_{i, 2}$ were set at $10 \%$ and $30 \%$ of the specimen strength and adjusted according to the orthotropic directions. The Poisson's ratios $v$, defined as the strain ratio of the passive (lateral) strain component $\varepsilon_{i}$ and the active strain component in the load direction $\varepsilon_{j}$,

$$
v_{i j}=-\frac{\varepsilon_{i}}{\varepsilon_{j}}, \quad i, j \in R, L, T \text { and } i \neq j
$$

were determined in the linear elastic range from the linear regression of the passive-active strain diagram. Because the surface area of the TL plane on the Te specimen in the L direction was insufficient for the strain calculation (Figure 1a), the $v_{\mathrm{TL}}$ was not gaugeable. The $v_{\mathrm{TL}}$ values were therefore calculated from the relationship between the elastic coefficients given by Bodig and Jayne (1993):

$$
v_{\mathrm{TL}}=v_{\mathrm{LT}} \cdot E_{\mathrm{L}} \cdot E_{\mathrm{T}}^{-1} .
$$

Two different strength criteria, the ultimate stress $\sigma_{\text {uS }}$ and the yield stress $\sigma_{\mathrm{Y}}$, were used to characterize the Te and Co strength properties of wood in all orthotropic directions. Using the following relationship:

$$
\sigma_{\mathrm{US}}=\frac{P_{\max }}{A},
$$

the $\sigma_{\text {US }}$ was calculated from the maximum load $P_{\max }$ at the point of failure and the cross-sectional area $A$ of the unloaded specimen. The $\sigma_{\mathrm{Y}}$, representing the stress at the specific yield point, was obtained from the measured stress-strain diagram based on the "offset yield method" at $0.2 \%$ plastic strain (Figure 2 ).

\section{Results and discussion}

\section{Young's moduli}

The Young's moduli presented in Table 1 clearly indicate a decreasing trend with increasing MC in all orthotropic

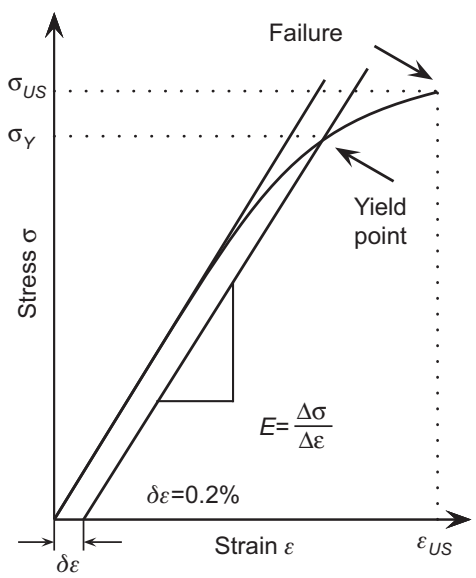

Figure 2 Determination of the yield stress $\sigma_{\mathrm{Y}}$ and the ultimate stress $\sigma_{\text {US }}$ from the stress-strain relationship.

directions and support the general findings published for European beech wood in Wommelsdorf (1966), Hering et al. (2012a), and Ozyhar et al. (2012a). The Te ( $\left.E^{\mathrm{Te}}\right)$ and the Co $\left(E^{\mathrm{Co}}\right)$ Young's moduli decrease with $\mathrm{MC}$ and reach their lowest values at $\omega=16.3 \%$; however, their maxima appear at different MCs. Whereas the $E^{\text {Te }}$ increases continuously with decreasing MC up to $\omega \approx 0 \%$, the maximum $E^{\mathrm{Co}}$ is reached at $\omega=5.9 \%$ for the $\mathrm{L}$ direction and at $\omega=3.3 \%$ for the $\mathrm{R}$ and $\mathrm{T}$ directions. The corresponding $E^{\mathrm{Co}}$ values at $\omega \approx 0 \%$ are lower than those measured in the $\omega=3.3-5.9 \%$ range. A comparison of the $E^{\text {Te }}$ and $E^{\text {Co }}$ values further reveals a Te-Co inequality of the moduli, which becomes distinct for the $\mathrm{R}$ and the $\mathrm{T}$ directions and is unique to the lower MCs (Figure 3). Although no significant difference is found between $E^{\mathrm{Te}}$ and $E^{\mathrm{Co}}$ in the MC range from $\omega \approx 8$ to $\omega=16.3 \%$, the $E^{\mathrm{Co}}$ values measured between $\omega \approx 0$ and $\omega \approx 8 \%$ are significantly higher than the corresponding $E^{\mathrm{Te}}$ values.

Various testing arrangements, unequal or undefined loading rates, and specimen shapes are factors that exacerbate a direct comparison of the $E^{\mathrm{Te}}$ and $E^{\mathrm{Co}}$ values from various literature sources. Also, the Te and Co properties cannot be determined on the same specimen type in all anatomical directions. In the present study, the specimen shape chosen in the $\mathrm{R}$ and $\mathrm{T}$ directions guaranteed a similar stress-state development in the tested area (Figure $1 \mathrm{~b}$ and $\mathrm{c}$ ). The chance for a fair comparability of the results was further increased by the application of similar testing arrangements and the same evaluation methods for testing the elastic properties in Te and Co and by the fact that the values were determined on samples taken from the same wood material. In view of this and considering the low variability 


\begin{tabular}{|c|c|c|c|c|c|c|}
\hline \multirow[t]{2}{*}{$\bar{\omega}(\%)$} & \multicolumn{3}{|r|}{$\mathrm{Te}$} & \multicolumn{3}{|r|}{ Co } \\
\hline & $E_{\mathrm{L}}^{\mathrm{Te}}$ & $E_{\mathrm{R}}^{\mathrm{Te}}$ & $E_{\mathrm{T}}^{\mathrm{Te}}$ & $E_{\mathrm{L}}^{\mathrm{co}}$ & $E_{\mathrm{R}}^{\mathrm{Co}}$ & $E_{\mathrm{T}}^{\text {co }}$ \\
\hline \multicolumn{7}{|l|}{0.0} \\
\hline $\bar{x}(\mathrm{MPa})$ & 14540 & 1880 & 830 & 12950 & 2180 & 980 \\
\hline $\operatorname{CoV}(\%)$ & 13.6 & 5.2 & 13.6 & 17.4 & 6.5 & 9.2 \\
\hline$n(-)$ & 10 & 10 & 9 & 9 & 9 & 8 \\
\hline$\rho\left(\mathrm{kg} \mathrm{m}^{-3}\right)$ & 656 & 649 & 679 & 645 & 673 & 675 \\
\hline \multicolumn{7}{|l|}{3.3} \\
\hline $\bar{x}(\mathrm{MPa})$ & - & 1850 & 820 & - & 2330 & 1050 \\
\hline $\operatorname{CoV}(\%)$ & - & 5.8 & 10.3 & - & 10.4 & 8.7 \\
\hline$n(-)$ & - & 9 & 9 & - & 9 & 9 \\
\hline$\rho\left(\mathrm{kg} \mathrm{m}^{-3}\right)$ & - & 672 & 683 & - & 669 & 678 \\
\hline \multicolumn{7}{|l|}{4.7} \\
\hline $\bar{x}(\mathrm{MPa})$ & - & 1840 & 820 & - & 2200 & 990 \\
\hline $\operatorname{CoV}(\%)$ & - & 5.9 & 13.1 & - & 8.6 & 8.5 \\
\hline$n(-)$ & - & 10 & 9 & - & 7 & 9 \\
\hline$\rho\left(\mathrm{kg} \mathrm{m}^{-3}\right)$ & - & 669 & 684 & - & 673 & 677 \\
\hline \multicolumn{7}{|l|}{5.9} \\
\hline $\bar{x}(\mathrm{MPa})$ & 12020 & 1800 & 810 & 13270 & 2070 & 940 \\
\hline $\operatorname{CoV}(\%)$ & 14.5 & 6.7 & 11.2 & 16.4 & 7.7 & 8.6 \\
\hline$n(-)$ & 11 & 10 & 10 & 12 & 9 & 9 \\
\hline$\rho\left(\mathrm{kg} \mathrm{m}^{-3}\right)$ & 674 & 683 & 681 & 684 & 672 & 659 \\
\hline \multicolumn{7}{|l|}{6.7} \\
\hline $\bar{x}(\mathrm{MPa})$ & - & 1790 & 820 & - & 2030 & 920 \\
\hline $\operatorname{Cov}(\%)$ & - & 4.3 & 13.6 & - & 9.4 & 5.7 \\
\hline$n(-)$ & - & 9 & 9 & - & 9 & 7 \\
\hline$\rho\left(\mathrm{kg} \mathrm{m}^{-3}\right)$ & - & 658 & 667 & - & 674 & 656 \\
\hline \multicolumn{7}{|l|}{11.3} \\
\hline $\bar{x}(\mathrm{MPa})$ & 10560 & 1510 & 730 & 11060 & 1650 & 750 \\
\hline $\operatorname{CoV}(\%)$ & 12.5 & 8.1 & 10.3 & 23.2 & 11.5 & 9.1 \\
\hline$n(-)$ & 23 & 30 & 32 & 24 & 30 & 22 \\
\hline$\rho\left(\mathrm{kg} \mathrm{m}^{-3}\right)$ & 661 & 668 & 654 & 654 & 680 & 689 \\
\hline \multicolumn{7}{|l|}{14.3} \\
\hline $\bar{x}(\mathrm{MPa})$ & 9270 & 1340 & 600 & 9880 & 1390 & 620 \\
\hline $\operatorname{CoV}(\%)$ & 12.7 & 10.3 & 9.6 & 0.22 & 0.12 & 0.10 \\
\hline$n(-)$ & 10 & 17 & 15 & 17 & 14 & 14 \\
\hline$\rho\left(\mathrm{kg} \mathrm{m}^{-3}\right)$ & 659 & 698 & 661 & 639 & 679 & 690 \\
\hline \multicolumn{7}{|l|}{16.3} \\
\hline $\bar{x}(\mathrm{MPa})$ & 9200 & 1240 & 530 & 9140 & 1140 & 550 \\
\hline $\operatorname{CoV}(\%)$ & 19.7 & 13.1 & 6.7 & 23.8 & 13.2 & 10.9 \\
\hline$n(-)$ & 8 & 17 & 16 & 16 & 14 & 13 \\
\hline$\rho\left(\mathrm{kg} \mathrm{m}^{-3}\right)$ & 673 & 687 & 658 & 639 & 682 & 687 \\
\hline
\end{tabular}

Table 1 Moisture-dependent Young's moduli for European beech wood in Te and Co.

$E^{\mathrm{Te}}$, Young's moduli determined in Te; $E^{\mathrm{C}}$, Young's moduli determined in $\mathrm{Co} ; \bar{\omega}$, average wood MC; $\bar{x}$, mean value; $\mathrm{CoV}$, coefficient of variation; $n$, number of specimens; $\rho$, wood density at $\bar{\omega}=11.3 \%$.

of the $E^{\mathrm{Te}}$ and $E^{\mathrm{Co}}$, the Te-Co asymmetry of the moduli in the $\mathrm{R}$ and $\mathrm{T}$ directions was found to be remarkable (Table 1). The results might at first appear inconsistent with the equality of the Te and Co Young's moduli often assumed for wood (Kollmann and Cote 1984; Niemz 1993); however, the equality of the $E^{\text {Te }}$ and $E^{\text {Co }}$ has not

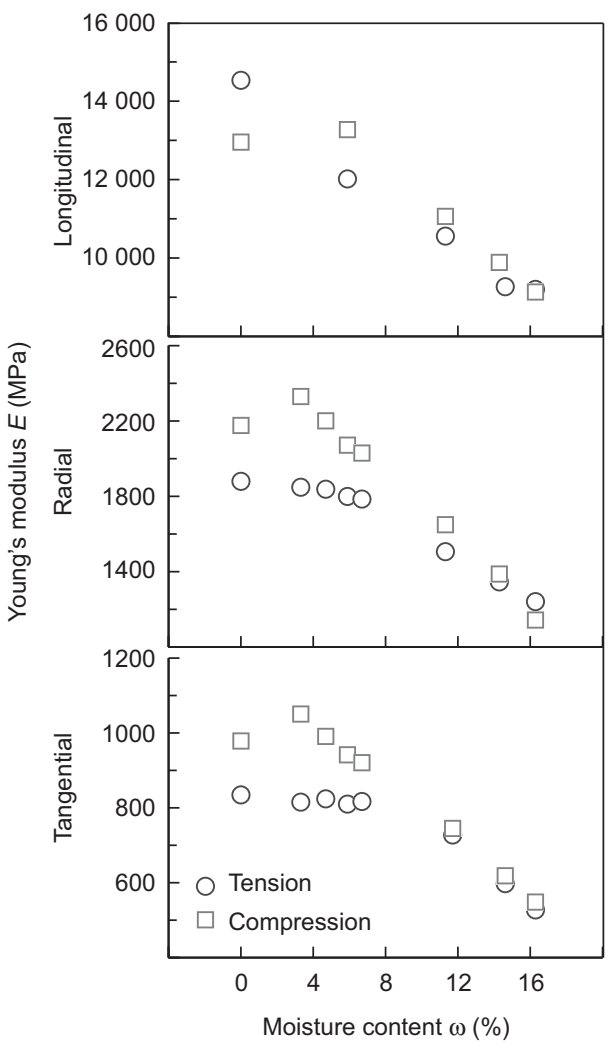

Figure 3 Comparison of the moisture-dependent Young's moduli for European beech wood determined in Te and Co.

yet been experimentally proven for a wide MC range. According to Conners and Medvecz (1992), the "assumption of moduli equality seems to be more firmly rooted in tradition than in factual evidence."

It was shown that many natural and synthetic materials exhibit an elastic behavior that differs in Te and Co (Curnier et al. 1995; Jones 2009). According to Jones (2009), this phenomenon is known as bimodular behavior. Examples of such behavior are given for a variety of materials, including nacre, rock, concrete, asphalt, bone, rubber, ceramics, graphite, and fiber-reinforced and granular composite materials (Zemlyakov 1965; Feldman 1987; Guo and Zhang 1987; Stimpson and Chen 1993; Bertoldi et al. 2008; Barak et al. 2009; Destrade et al. 2010; Katicha et al. 2011). A bimodular behavior for wood was demonstrated by Conners and Medvecz (1992), who reported that the $E^{\mathrm{Co}}$ in the L direction for yellow poplar was higher than the $E^{\text {Te }}$ and the relationship was moisture dependent. Although the results of the present study are slightly different, the $E^{\mathrm{Te}} / E^{\mathrm{Co}}$ ratio confirms the existence of moisturedependent bimodular behavior for the $\mathrm{R}$ and $\mathrm{T}$ directions (Figure 4). The results show that the $E^{\mathrm{Co}}$ values in these directions are higher than the corresponding $E^{\mathrm{Te}}$ and the 


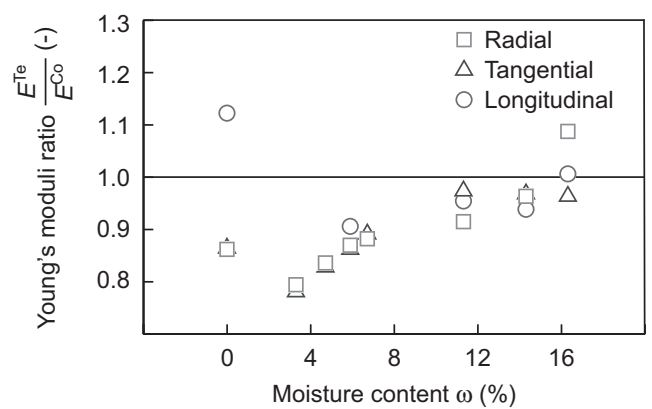

Figure 4 Te-Co Young's moduli ratio $E^{\mathrm{Te}} / E^{\mathrm{Co}}$ as a function of MC.

asymmetry is most pronounced at MCs ranging from $\omega \approx 0$ to $\omega \approx 8 \%$, indicating a weakening trend with increasing MC. Although the averaged difference between the $E^{\mathrm{Co}}$ and the $E^{\mathrm{Te}}$ at $\omega=3.3 \%$ amounts to $\approx 21 \%$, the Te and Co moduli at $\omega \approx 15 \%$ can be assumed to be equal.

The interpretation of the above finding is currently speculative. Water sorption at the molecular level can be one reason, at which hydrogen linkages ("H-bridges") are participating between $\mathrm{OH}$ groups in the cell wall (mainly of the polysaccharides) and the water molecules (Hill et al. 2010). A complete molecular sorption of water is reached at 6\% MC and a monomolecular layer covers the interior surfaces of wood. At lower MC levels, the water monolayer is slowly vanishing and the approximately 100 times weaker van der Waals linkages with their shorter distances become active. It is perhaps possible that even some covalent bonds in the cell wall may break in the course of this process (Stamm 1964). Because the stressstrain relationship in wood is a function of the chemical bond strength (Winandy and Rowell 2005), the stiffness below $6 \% \mathrm{MC}$ is expected to be negatively affected. Especially, the weakening of the secondary bonds (van der Waals linkages instead of hydrogen linkages) at the interface between the primary cell wall and the middle lamella would definitely affect the stiffness of the cell assembly. It is assumed that such chemical debonding will interrupt the elastic stress transfer in Te, consequently weakening the Te stiffness while leaving the $E^{\mathrm{co}}$ unimpaired. The differences in the elastic load transfer in Te and Co are known for structures with debonded composites and the topic has been discussed for materials other than wood (Benveniste 1985). It was demonstrated that, for a matrix composite with debonded fibers, the $E^{\text {Te }}$ in the transverse to the fiber direction is lower than the corresponding $E^{\mathrm{Co}}$, whereas, in the case of perfect bonding conditions, the $E^{\mathrm{Te}}$ and $E^{\mathrm{Co}}$ are equal (Takhashi and Chou 1988; Turovtsev and Toropov 2005). According to the latter authors, the inequality of the $E^{\mathrm{Co}}$ and $E^{\mathrm{Te}}$ in a composite with debonded fibers is associated with the decline in the elastic load transfer in Te. Although the mechanical behavior of a fiber matrix composite and wood is not comparable, the fiber matrix can serve as a model system, in which the fibers are equivalent to the cellulose chains in the hemicellulose-lignin matrix in wood. Similar curves with a flattening slope for the $E^{\text {Te }}$ at low MC levels as shown in Figure 3 were reported by Östman (1985) and for individual wood fibers by Kersavage (1973).

The elastic load transfer influencing the $E^{\text {Te }}$ might also arise from nanocracks or microcracks induced during drying below 6\% MC (Sakagami et al. 2009). The development of microchecks in the cell wall associated with increased brittleness of the cellulose at low MC was mentioned by Kersavage (1973). The microcracks could interrupt the elastic load distribution in Te and lower the $E^{\mathrm{Te}}$, as discussed for chemical debonding. The material observed in this study was carefully dried, but the presence of such imperfections cannot be completely excluded.

It is also conceivable that the bimodular behavior might be generated by a different elastic response of the material in Te and Co. According to Winandy and Rowell (2005), it is likely that, even at low stress levels in the elastic range, permanent set or distortion will be introduced in a wood section. Wood, often simplified as a linear elastic material, is a complex nanocomposite with a hierarchical structure of components (Salmén and Burgert 2009; Stevanic and Salmén 2009), which in reality is characterized by a viscoelastic behavior (Schniewind and Barrett 1972). Distortions on the microlevel and nanolevel could result in a different elastic stress distribution in Te and Co. This could lead to a different elastic behavior observable at the macroscopic level, despite this behavior being clearly influenced by MC.

\section{Poisson's ratios}

The Poisson's ratios are characterized by a high variability as indicated by the high $\operatorname{CoV}$ (Table 2) that, according to Hering et al. (2012a), is attributable to the high natural variability. A similar high variability has also been presented by Keunecke et al. (2008).

The results show only a marginal influence of MC on the Poisson's ratios (Figure 5). The $v_{\mathrm{TR}}$ in Te and the $v_{\mathrm{LR}}$ in Co decrease slightly with increasing MC overall; however, the Poisson's ratios appear to be rather insensitive to MC. This is different from the moisture-dependent trend reported by Hering et al. (2012a), who found a 


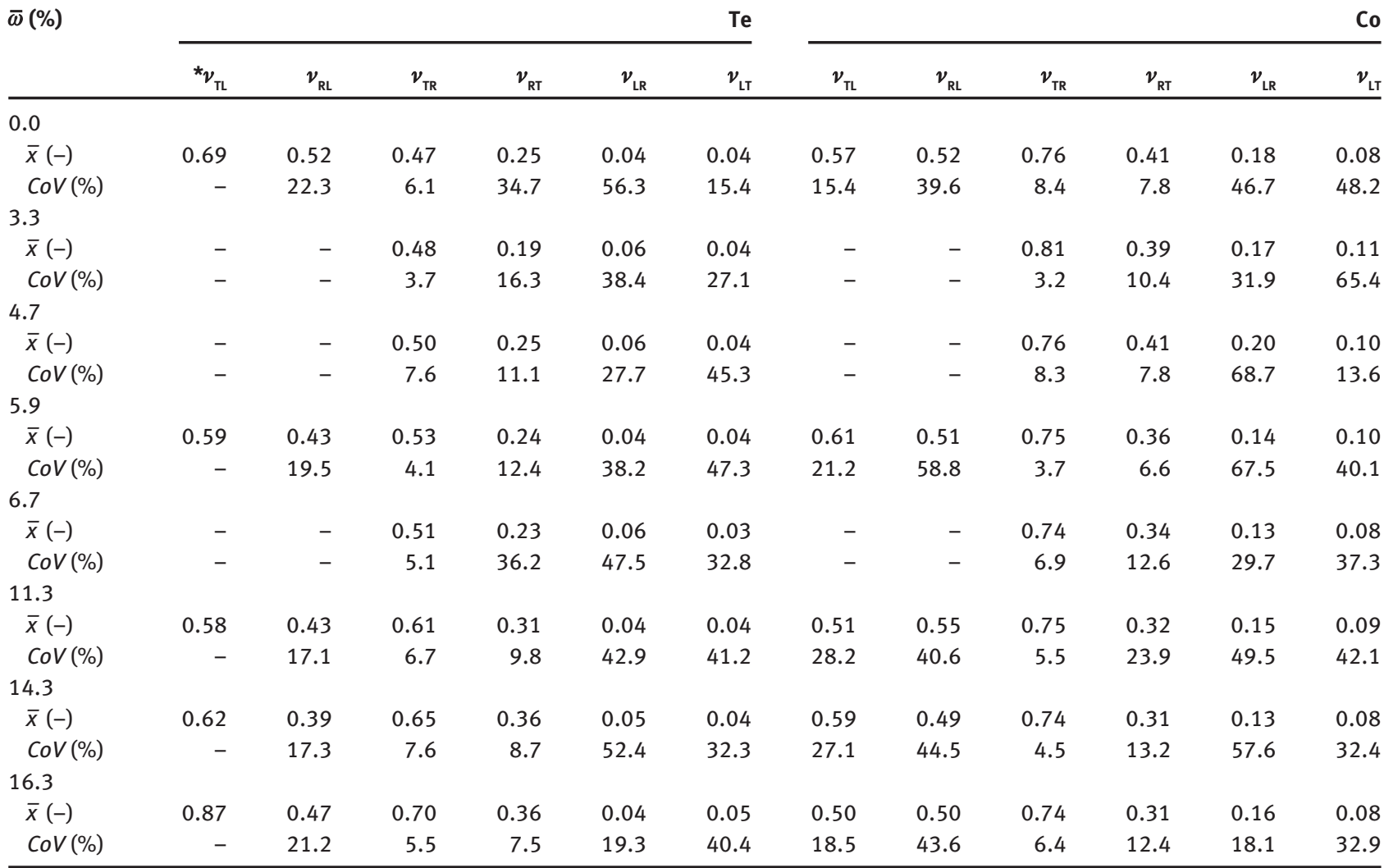

Table 2 Moisture-dependent Te and Co Poisson's ratios for beech wood *Value calculated from Eq. (3). $v$, Poisson's ratios; $\bar{\omega}$, average wood MC; $\bar{x}$, mean value; CoV, coefficient of variation.

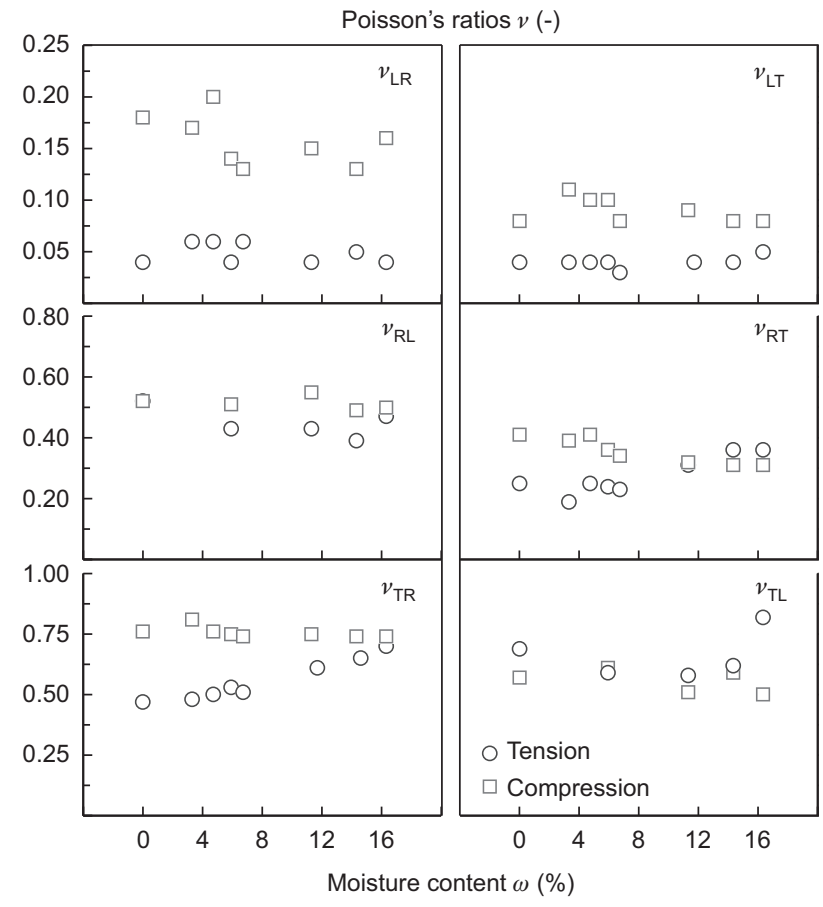

Figure 5 Comparison of the moisture-dependent Poisson's ratios for European beech wood determined in Te and Co. slightly decreasing tendency with increasing MC for European beech wood, and McBurney and Drow (1962), who determined that some of the Poisson's ratios of Douglas fir (based partially on data calculated from elastic constants) were found to increase, whereas others were found to decrease with increasing MC. Different wood species, varying specimen shapes, and unequal loading conditions might be the reason for deviating trends in the literature.

Poisson's ratio values in Te and Co (Figure 5) indicate that the loading direction (Te and $\mathrm{Co}$ ) appears to have a greater influence on the values than the MC. The inequalities between Te and Co values are most pronounced for the $v_{\mathrm{LR}}$ and $v_{\mathrm{TR}}$ and, to a lesser extent, for $v_{\mathrm{LT}}$ and $v_{\mathrm{RT}}$, whereby the Poisson's ratios in Co, in general, are higher than the corresponding values in Te. The lack of data on the Te-Co relationship of wood's Poisson's ratios prevents a verification of the results. Research done on other biological materials with distinctive anisotropy and hierarchical structures, like bone, however, have shown a distinctive Te-Co asymmetry for the Poisson's ratios (Chahine et al. 2004). 


\section{Strength behavior}

The comparison of the Te and Co strength behavior of wood in the L direction is straightforward. The strength properties that describe the behavior in this direction are given by the ultimate stress $\sigma_{\mathrm{US}}$, that is, the stress reached at failure ( $\sigma_{\text {UTS }}$ is ultimate Te stress for Te and $\sigma_{\text {UCS }}$ is ultimate Co stress for Co). However, this approach is not adaptable to describe the Te-Co strength relationship in the $\mathrm{R}$ and $\mathrm{T}$ directions. The Co strength behavior of wood in the $\mathrm{R}$ and $\mathrm{T}$ directions is characterized by the absence of clear failure (Gibson and Ashby 1988; Bodig and Jayne 1993), and no $\sigma_{\text {US }}$ value in these directions exists. Consequently, the $\sigma_{\mathrm{US}}$ criterion is not applicable to describe the Te-Co strength relationship in these directions. An alternative strength criterion is given by the definition of the yield stress $\sigma_{\mathrm{Y}}$ (Figure 2). Introduced in several standards, the $\sigma_{\mathrm{Y}}$ is an easily quantifiable strength value that is used as the strength criterion for other materials such as metals and plastics. Defined as the stress at $0.2 \%$ plastic strain (based on the ASTM-E8/E8M-11 (2011) standard for Te testing of metallic materials), the $\sigma_{\mathrm{y}}$ allows a direct strength comparison with other (particularly metallic) materials.

In the present study, the $\sigma_{\mathrm{Y}}$ was determined in the same manner in Te $\left(\sigma_{\mathrm{Y}}^{\mathrm{Te}}\right)$ and Co $\left(\sigma_{\mathrm{Y}}^{\mathrm{Co}}\right)$; data are compared in Table 3). It becomes obvious that the Te and Co strengths are affected significantly by MC (Table 3). Similar to the Young's moduli, the lowest strength is reached at $\omega=16.3 \%$ and increases continuously with decreasing MC in all orthotropic directions. Differently than for the $E^{\mathrm{Co}}$, the maximum Co strength is reached at $\omega \approx 0 \%$, supporting the findings from literature summarized in Gerhards (1982). The ultimate Te stress $\sigma_{\text {UTS }}$, on the other hand, is reached at $\omega=5.9 \%, \omega=3.3 \%$, and $\omega=4.7 \%$ in the $\mathrm{L}, \mathrm{R}$, and $\mathrm{T}$ directions, respectively, indicating a strength decline at lower MCs (Figure 6). Similar findings showing that drying below a certain point leads to reduced strengths were reported (Goulet 1960; Kufner 1978; Kretschmann and Green 1996). Based on the mentioned references, the optimum $\sigma_{\text {UTS }}$ is reached at MCs $\omega \approx 4-12 \%$ depending on the wood species and the orthotropic direction. Note that the results at $\omega \approx 0 \%$, although particularly valuable, may not be directly

\begin{tabular}{|c|c|c|c|c|c|c|c|c|c|c|c|c|}
\hline \multirow[t]{3}{*}{$\bar{\omega}(\%)$} & \multicolumn{8}{|r|}{$\mathrm{Te}$} & \multicolumn{4}{|c|}{ Co } \\
\hline & \multicolumn{2}{|r|}{$\mathbf{L}$} & \multicolumn{3}{|r|}{$\mathbf{R}$} & \multicolumn{3}{|r|}{$\mathbf{T}$} & \multicolumn{2}{|r|}{$\mathbf{L}$} & \multirow{2}{*}{$\begin{array}{r}R \\
\begin{array}{r}\sigma_{\mathrm{Y}}^{\mathrm{co}} \\
\left(\mathrm{N} \mathrm{mm}^{-2}\right)\end{array}\end{array}$} & \multirow{2}{*}{$\begin{array}{r}\sigma_{\mathrm{Y}}^{\mathrm{cc}} \\
\left(\mathrm{N} \mathrm{mm}^{-2}\right)\end{array}$} \\
\hline & $\begin{array}{r}\sigma_{\text {UTs }} \\
\left(\mathrm{N} \mathrm{mm}^{-2}\right)\end{array}$ & $\begin{array}{l}\varepsilon_{\mathrm{UTS}} \\
(\%)\end{array}$ & $\begin{array}{r}\sigma_{\text {UTS }} \\
\left(\mathrm{N} \mathrm{mm}^{-2}\right)\end{array}$ & $\begin{array}{r}\sigma_{\mathrm{Y}}^{\mathrm{Te}} \\
\left(\mathrm{N} \mathrm{mm}^{-2}\right)\end{array}$ & $\begin{array}{l}\varepsilon_{\mathrm{UTS}} \\
(\%)\end{array}$ & $\begin{array}{r}\sigma_{\mathrm{UTS}} \\
\left(\mathrm{N} \mathrm{mm}^{-2}\right)\end{array}$ & $\begin{array}{r}\sigma_{\mathrm{r}}^{\mathrm{Te}} \\
\left(\mathrm{N} \mathrm{mm}^{-2}\right)\end{array}$ & $\begin{array}{l}\varepsilon_{\text {UTS }} \\
(\%)\end{array}$ & $\begin{array}{r}\sigma_{\text {UTs }} \\
\left(\mathrm{N} \mathrm{mm}^{-2}\right)\end{array}$ & $\begin{array}{l}\varepsilon_{\text {ucs }} \\
(\%)\end{array}$ & & \\
\hline \multicolumn{13}{|l|}{0.0} \\
\hline $\bar{x}$ & 105.2 & 0.80 & 17.9 & 16.0 & 0.92 & 8.9 & 8.4 & 1.0 & 86.2 & 1.35 & 16.6 & 8.5 \\
\hline $\operatorname{CoV}(\%)$ & 20.4 & 12.4 & 2.8 & 5.6 & 6.3 & 15.7 & 19.0 & 12.1 & 13.5 & 27.0 & 8.0 & 6.5 \\
\hline \multicolumn{13}{|l|}{3.3} \\
\hline $\bar{x}$ & - & - & 22.2 & 20.9 & 1.24 & 12.1 & 10.0 & 1.7 & - & - & 15.7 & 8.1 \\
\hline $\operatorname{CoV}(\%)$ & - & - & 3.4 & 9.5 & 6.5 & 9.6 & 8.0 & 11.0 & - & - & 6.7 & 8.2 \\
\hline \multicolumn{13}{|l|}{4.7} \\
\hline $\bar{x}$ & - & - & 21.0 & 20.1 & 1.23 & 12.8 & 9.4 & 1.8 & - & - & 15.3 & 8.2 \\
\hline $\operatorname{CoV}(\%)$ & - & - & 6.0 & 6.7 & 6.5 & 14.2 & 6.8 & 16.0 & - & - & 4.8 & 6.5 \\
\hline \multicolumn{13}{|l|}{5.9} \\
\hline $\bar{x}$ & 115.3 & 0.98 & 21.4 & 18.2 & 1.38 & 11.4 & 8.8 & 1.76 & 68.9 & 1.21 & 14.4 & 7.7 \\
\hline $\operatorname{CoV}(\%)$ & 24.5 & 10.3 & 4.4 & 6.9 & 5.1 & 16.8 & 7.5 & 10.6 & 6.5 & 19.5 & 3.4 & 6.1 \\
\hline \multicolumn{13}{|l|}{6.7} \\
\hline $\bar{x}$ & - & - & 21.0 & 17.3 & 1.4 & 11.6 & 8.5 & 1.8 & - & - & 13.7 & 7.5 \\
\hline $\operatorname{CoV}(\%)$ & - & - & 4.3 & 18.2 & 10.3 & 15.2 & 4.0 & 17.3 & - & - & 6.0 & 8.4 \\
\hline \multicolumn{13}{|l|}{11.3} \\
\hline $\bar{x}$ & 96.7 & 1.06 & 19.5 & 14.7 & 1.73 & 8.9 & 7.0 & 1.80 & 45.0 & 1.00 & 11.0 & 6.0 \\
\hline $\operatorname{CoV}(\%)$ & 28.4 & 19.3 & 9.9 & 15.3 & 12.6 & 18.4 & 6.6 & 27.8 & 7.9 & 24.8 & 8.0 & 4.9 \\
\hline \multicolumn{13}{|l|}{14.3} \\
\hline $\bar{x}$ & 83.6 & 1.13 & 17.1 & 12.5 & 1.99 & 7.8 & 6.1 & 1.89 & 36.4 & 0.89 & 9.3 & 4.9 \\
\hline $\operatorname{CoV}(\%)$ & 16.9 & 14.2 & 9.5 & 11.5 & 25.4 & 10.3 & 7.7 & 24.6 & 12.1 & 26.8 & 8.6 & 4.3 \\
\hline \multicolumn{13}{|l|}{16.3} \\
\hline $\bar{x}$ & 80.6 & 1.11 & 15.6 & 10.9 & 2.06 & 7.3 & 5.9 & 1.93 & 31.7 & 0.75 & 8.0 & 4.4 \\
\hline $\operatorname{CoV}(\%)$ & 2.1 & 20.0 & 11.9 & 10.5 & 21.3 & 11.8 & 5.2 & 25.0 & 10.8 & 26.5 & 8.9 & 5.7 \\
\hline
\end{tabular}

Table 3 Moisture-dependent strength properties for European beech wood in Te and Co.

$\sigma_{\text {UTS }}$, ultimate Te stress; $\sigma_{\text {ucs }}$, ultimate Co stress; $\sigma_{\mathrm{Y}}^{\text {Te }}$, Te yield stress; $\sigma_{\mathrm{Y}}^{\mathrm{Co}}$, Co yield stress; $\varepsilon_{\text {UTS }}$, strain at $\sigma_{\text {UTS }} ; \varepsilon_{\text {ucS }}$, strain at $\sigma_{\text {ucs }} ; \bar{\omega}$, average wood MC; $\bar{x}$, mean value; CoV, coefficient of variation. 


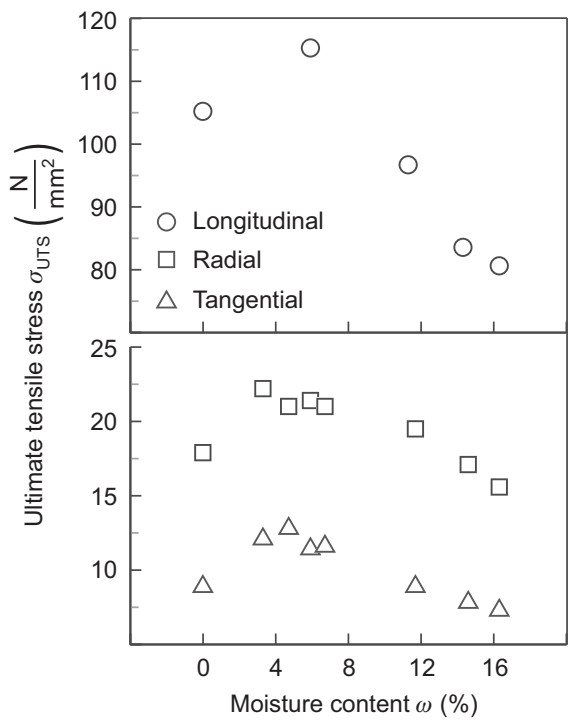

Figure 6 Moisture-dependent ultimate Te stress $\sigma_{\text {UTS }}$ for European beech wood.

comparable to other MCs, as the impact on the mechanical behavior via nanocracks and microcracks has not yet been clarified.

Under standard climatic conditions, wood in the L direction exhibits approximately double the strength in $\mathrm{Te}$ than in Co (Kollmann and Cote 1984). According to Raczkowski et al. (1995), the Te-Co strength ratio at $\omega=12.0 \%$ for European beech wood amounts to 2.4. The Te-Co strength ratio of 2.1 obtained at $\omega=11.3 \%$ supports those findings; however, the Te-Co strength asymmetry extends with increasing MC (Figure 7a). With a strength ratio of 1.2 at $\omega \approx 0 \%$ in the $\mathrm{L}$ direction, the ratio is less than half of the ratio obtained at $\omega=16.3 \%$. It is obvious that the Te-Co strength asymmetry is driven mainly by changes in the Co strength. Although the decrease in Te strength measured between $\omega \approx 0 \%$ and $\omega=16.3 \%$ in the $L$ direction amounts to $23 \%$, the corresponding decrease in Co equals to $63 \%$. In contrast to the $\mathrm{L}$ direction, the strength ratio in the $\mathrm{R}$ and $\mathrm{T}$ directions is influenced by $\mathrm{MC}$ to a much lesser degree. The moisture-dependent ratio for all MC levels averages $\approx 1.3$ and applies to both $\mathrm{R}$ and $\mathrm{T}$ directions.

The strength asymmetry in-between the principal axes is visualized in Figure 7b. Represented by the Te-Co yield surface ratios (determined by applying the yield criterion given in Resch and Kaliske 2010 and Saft and Kaliske 2011 using the $\sigma_{\mathrm{Y}}$ from Table 3), the moisture-dependent orthotropic Te-Co strength asymmetry is presented for all planes of anisotropy. It should be emphasized that the yield surface ratios are used exclusively as a description of the strength behavior in-between the principal axes. Note that, due to the stress-strain relationship in the L direction, the $\sigma_{\mathrm{Y}}$ in Te is equal to $\sigma_{\mathrm{UTS}}$ and the $\sigma_{\mathrm{Y}}$ in Co is equal to $\sigma_{\mathrm{UCS}}$.

\section{Conclusions}

The orthotropic mechanical behavior of wood is significantly influenced by MC. Experimental data for beech wood reveal a distinctive Te-Co asymmetry of the mechanical behavior, which depends on MC. Demonstrated by the Te-Co strength asymmetry, the moisture-dependent inequalities between the Te and the Co behaviors are also shown for the elastic properties. Known as the "bimodular behavior", the elastic Te-Co asymmetry is demonstrated by the Young's moduli in the $\mathrm{R}$ and $\mathrm{T}$ directions and individual Poisson's ratios. The obtained bimodularity questions the applicability of the theory of perfect elasticity used to describe the elastic behavior of wood. Although, for practical applications and under normal conditions, a

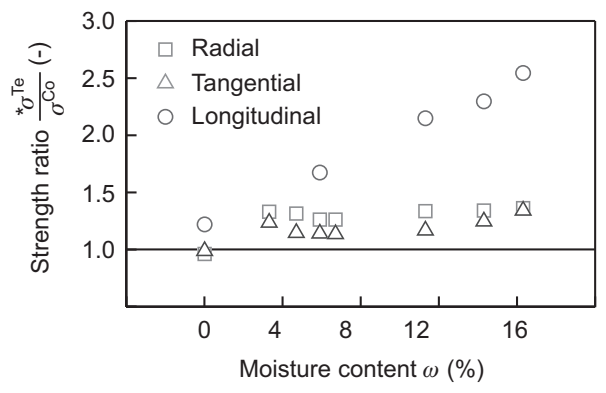

b

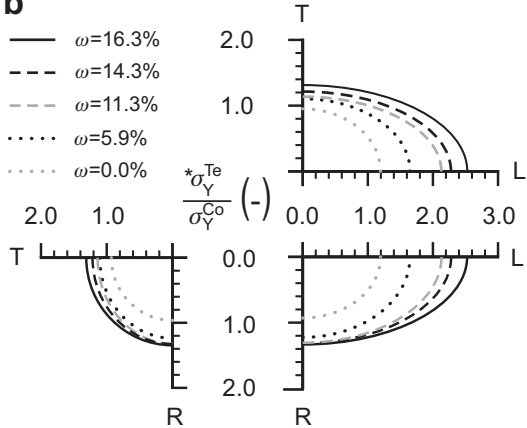

Figure 7 (a) Moisture-dependent Te-Co strength ratio $\left(\sigma^{\mathrm{Te}} / \sigma^{\mathrm{co}}\right)$ for European beech wood (* corresponds to $\sigma_{\text {UTS }} / \sigma_{\text {UCS }}$ in the L direction and $\sigma_{Y}^{\text {Te }} / \sigma_{Y}^{\text {Co }}$ in the R and T directions, respectively).

(b) Moisture-dependent Te-Co yield surface ratio for European beech wood (yield surface as defined in Resch and Kaliske 2010 and Saft and Kaliske 2011). 
the equality assumption of the elastic properties in $\mathrm{Te}$ and Co might be justified, under specific conditions, bimodularity must be seriously considered. Neglecting the inequality of the elastic behavior might have consequences for sophisticated simulations, leading to inaccurate results.

\section{References}

American Society for Testing and Materials (2011) ASTM-E8/ E8M-11. Standard Test Methods for Tension Testing of Metallic Materials.

American Society for Testing and Materials (2007) ASTM-D442-92. Standard Test Methods for Direct Moisture Content Measurements of Wood and Wood-Base Materials.

Barak, M.M., Curreyb, J.D., Weinera, S., Shahar, R. (2009) Are tensile and compressive Young's moduli of compact bone different? J. Mech. Behav. Biomed. 2:51-60.

Benveniste, Y. (1985) The effective mechanical behaviour of composite materials with imperfect contact between the constituents. Mech. Mater. 4:197-208.

Bertoldi, K., Bigoni, D., Drugan, W.J. (2008) Nacre: an orthotropic and bimodular elastic material. Compos. Sci. Technol. 68:1363-1375.

Bodig, J., Jayne, B.A. Mechanics of Wood and Wood Composites. Krieger Publishing Co., Malabar, 1993.

Chahine, N.O., Wang, C.C., Hung, C.T., Ateshian, G.A. (2004) Anisotropic strain-dependent material properties of bovine articular cartilage in the transitional range from tension to compression. J. Biomech. 37:1251-1261.

Conners, T.E., Medvecz, C.J. (1992) Wood as a bimodular material. Wood Fiber Sci. 24:413-423.

Curnier, A., He, Q., Zysset, P. (1995) Conewise linear elastic materials. J. Elast. 37:1-38.

Destrade, M., Gilchrist, M.D., Motherway, J.A., Murphy, J.G. (2010) Bimodular rubber buckles early in bending. Mech. Mater. 42:469-476.

Deutsches Institut für Normung e. V. (1976) 52185 DIN 1976-09. Prüfung von Holz; Bestimmung der Druckfestigkeit parallel zur Faser.

Deutsches Institut für Normung e. V. (1979) 52188 DIN 1979-05. Prüfung von Holz; Bestimmung der Zugfestigkeit parallel zur Faser.

Deutsches Institut für Normung e. V. (1979) 52192 DIN 1979-05. Prüfung von Holz; Druckversuch quer zur Faser.

Feldman, L.A. (1987) Bimodular behaviour and crack closure in compression in a brittle material. J. Mater. Sci. 22:2789-2792.

Gerhards, C.C. (1982) Effect of moisture content and temperature on the mechanical properties of wood: an analysis of immediate effects. Wood Fiber Sci. 14:4-36.

Gibson, L.J., Ashby, M.F. Cellular Solids. Structure and Properties. Pergamon Press, Oxford, 1988.

Goulet, M. (1960) Die Abhängigkeit der Querzugfestigkeit von Eichen, Buchen und Fichtenholz von Feuchtigkeit und Temperatur im Bereich von $0^{\circ}$ bis $100^{\circ} \mathrm{C}$. Holz Roh. Werkst. 18:325-331.

Greenspan, L. (1977) Humidity fixed points of binary saturated aqueous solutions. J. Res. Nat. Bur. Stand-A Phys. Chem. 81A:89-96.
Acknowledgments: The authors thank the Bundesamt für Umwelt, Fonds zur Förderung der Wald und Holzforschung, for the financial contribution to this research.

Received July 1, 2012; accepted October 31, 2012; previously published online December 8, 2012

Guo, Z., Zhang, X. (1987) Investigation of complete stressdeformation curves for concrete in tension. ACI Mater. J. 84:278-285.

Hering, S., Keunecke, D., Niemz, P. (2012a) Moisture-dependent orthotropic elasticity of beech wood. Wood Sci. Technol. 45:927-938.

Hering, S., Saft, S., Resch, E., Niemz, P., Kaliske, M. (2012b) Characterisation of moisture-dependent plasticity of beech wood and its application to a multi-surface plasticity model. Holzforschung 66:373-380.

Hill, C.A.S., Norton, A.J., Newman, G. (2010) The water vapour sorption properties of Sitka spruce determined using a dynamic vapour sorption apparatus. Wood Sci. Technol. 44:497-514.

Jones, R.M. Deformation theory of plasticity. Bull Ridge Publishing, Blacksburg, VA, 2009.

Katicha, S.W., Flintsch, G., Loulizi, A. (2011) Bimodular analysis of hot-mix asphalt. Int. J. Road Mater. Pavement Design 11:917946.

Kersavage, P.C. (1973) Moisture content effect on tensile properties of individual Douglas-fir latewood tracheids. Wood Fiber Sci. 5:105-117.

Keunecke, D., Hering, S., Niemz, P. (2008) Three-dimensional elastic behaviour of common yew and Norway spruce. Wood Sci. Technol. 42:633-647.

Kollmann, F. (1956) Untersuchungen über die Querzugfestigkeit der Hölzer. Forstwiss. Centralbl. 75:304-318.

Kollmann, F.F.P., Cote, W.A. Principles of Wood Science and Technology. Springer-Verlag, Berlin, 1984.

Kretschmann, D.E., Green, D.W. (1996) Modelling moisture contentmechanical property relationships for clear southern pine. Wood Fiber Sci. 28:320-337.

Kufner, M. (1978) Elastizitätsmodul und Zugfestigkeit von Holz verschiedener Rohdichte in Abhängigkeit vom Feuchtigkeitsgehalt. Holz Roh. Werkst. 36:435-439.

McBurney, R.S., Drow, J.T. (1962) The Elastic Properties of Wood: Young's Moduli and Poisson's Ratios of Douglas-Fir and Their Relations to Moisture Content. Forest Product Laboratory Report No. 1528-D, U.S. Department of Agriculture, Forest Service, Forest Products Laboratory, Madison, WI.

Neuhaus, F.H. (1983) Über das elastische Verhalten von Fichtenholz in Abhängigkeit von der Holzfeuchtigkeit. Holz Roh. Werkst. 41:21-25.

Niemz, P. Physik des Holzes und der Holzwerkstoffe. DRW-Verlag Weinbrenner GmbH \& Co., Leinfelden-Echterdingen, 1993.

Östman, B.A.L. (1985) Wood tensile strength at temperatures and moisture contents simulating fire conditions. Wood Sci. Technol. 19:103-116. 
Ozyhar, T., Hering, S., Sanabria, S.J., Niemz, P. (2012a) Determining moisture-dependent elastic characteristics of beech wood by means of ultrasonic waves. Wood Sci. Technol. Online First, DOI: $10.1007 / \mathrm{s} 00226-012-0499-2$.

Ozyhar, T., Hering, S., Niemz, P. (2012b) Moisture-dependent elastic and strength anisotropy of European beech wood in tension. J. Mater. Sci. 47:6141-6150.

Raczkowski, J., Jakubów, S., Majchrzak, A. (1995) Zależność między wytrzymałością drewna na rozciąganie i ściskanie wzdłuż włókien. Wpływ wilgotności. Folia Forestalia Polonica B 26:151-159.

Resch, E., Kaliske, M. (2010) Three-dimensional numerical analyses of load-bearing behavior and failure of multiple double-shear dowel-type connections in timber engineering. Comput. Struct. 88:165-177.

Ross, R.J. (Ed.) (2010) Wood Handbook: Wood as an Engineering Material. General Technical Report FPL-GTR 190, U.S. Department of Agriculture, Forest Service, Forest Products Laboratory, Madison, WI.

Saft, S., Kaliske, M. (2011) Numerical simulation of the ductile failure of mechanically and moisture loaded wooden structures. Comput. Struct. 89:2460-2470.

Salmén, L., Burgert, I. (2009) Cell wall features with regard to mechanical performance. A review. COST Action E35 2004-2008: Wood machining - micromechanics and fracture. Holzforschung 63:121-129.

Sakagami, H., Matsumura, J., Oda, K. (2009) In situ visualization of hardwood microcracks occurring during drying. J. Wood Sci. 55:323-328.
Schniewind, A.P., Barrett, J.D. (1972) Wood as a linear orthotropic viscoelastic material. Wood Sci. Technol. 6:43-57.

Stamm, A.J. Wood and Cellulose Science. Ronald Press Co., New York, 1964.

Stevanic, J.S., Salmén, L. (2009) Orientation of the wood polymers in the cell wall of spruce wood fibres. Holzforschung 63: 497-503.

Stimpson, B., Chen, R. (1993) Measurement of rock elastic moduli in tension and in compression and its practical significance. Can. Geotech. J. 30:338-347.

Takhashi, K., Chou, T.W. (1988) Transverse elastic moduli of undirectional fiber composites with interfacial debonding. Metall. Mater. Trans. A 19:129-135.

Tiemann, H.D. (1906) Effect of moisture upon the strength and stiffness of wood. Forest Service Bulletin 70, U.S. Department of Agriculture.

Turovtsev, G.V., Toropov, V.V. (2005) Identification of Fiber Composite Interface Properties using Changes in Natural Frequencies, 6th World Congresses of Structural and Multidisciplinary Optimatization, Rio de Janeiro.

Winandy, J.E., Rowell, R.M. (2005) Chemistry of Wood Strength. In: Handbook of Wood Chemistry and Wood Composites. (Ed.) Rowell, R.M. CRC Press, Madison, WI. pp. 303-347.

Wommelsdorf, O. (1966) Dehnungs- und Querdehnungszahlen von Hölzern. Dissertation, Technische Hochschule Hannover.

Zemlyakov, I.P. (1965) On the difference in the moduli of elasticity of polyamides subjected to different kinds of deformation. Mech. Compos. Mater. 1:25-27. 